\title{
EDITORIAL
}

\section{Cuarenta y cinco años de Salud Pública de México}

D urante el verano de 1959, unos meses antes de que la vacuna antipoliomielítica preparada por Albert Sabin fuera liberada para ser aplicada en todo el mundo, nació la revista Salud Pública de México. Inicialmente, la revista fue concebida por los doctores José Alvarez Amézquita y Miguel E. Bustamante como una continuación de las actividades que durante 120 años había desarrollado el Boletín del Consejo Superior de Salubridad del Distrito Federal, el cual fue por más de un siglo el principal órgano difusor de la situación sanitaria mexicana. A partir de su nacimiento, Salud Pública de México emprendió la tarea de difundir entre los trabajadores de la entonces Secretaría de Salubridad y Asistencia los avances que las nacientes instituciones de investigación médica comenzaban a producir en el país.

Desde 1987 la responsabilidad de la revista recayó en el recién creado Instituto Nacional de Salud Pública y la necesidad de consolidarla como una revista científica se conjugó, desde ese momento, con el propósito de convertirla en un foro de debate académico entre los mexicanos preocupados por el desarrollo de una salud pública innovadora, abierta a los cambios experimentados en otras latitudes. Con este cambio, Salud Pública de México abandonó definitivamente su carácter de órgano informativo para convertirse en una de las mejores revistas especializadas en salud pública de América Latina.

Durante sus primeros 45 años de vida, la revista ha abierto sus páginas a todos aquellos científicos que buscan describir y comprender el complejo origen biológico, económico y cultural de los problemas colectivos de salud y aportar conocimientos para contribuir a su solución. En sus páginas se han publicado trabajos generados desde prácticamente todas las disciplinas relacionadas con la salud de la población, y son frecuentes los aportes conceptuales y metodológicos relativos a la salud, concebida como un todo. En la ac- tualidad, la revista aborda regularmente temas que no sólo conciernen a la epidemiología, la estadística médica y la administración hospitalaria, sino a la sociología y antropología médicas, la psicología social, la economía de la salud, la ciencia política, la epistemología y la ética. Asimismo, ha promovido la incorporación de los desarrollos instrumentales más avanzados en su campo y ha contribuido al debate sobre la dinámica y tendencia de problemas emergentes (tabaquismo, SIDA, SARS, lesiones, trastornos mentales, obesidad) y remergentes (cólera, tuberculosis). Esta apertura le ha consolidado como uno de los medios de comunicación científica más relevantes en su campo en América Latina y, en consecuencia, como un instrumento capaz de cerrar efectivamente el círculo producción-diseminación-utilización del conocimiento en los distintos campos de su especialidad. Este proceso se ha fortalecido con la publicación cada vez más frecuente de números monográficos dedicados al tratamiento científico de temas relevantes para la salud de la población.

Con motivo de su cuadragésimo quinto aniversario, Salud Pública de México realizará una serie de cambios a su imagen y contenido. En cuanto a la primera, desde el primer número del volumen 46 el lector habrá podido apreciar un cambio de imagen. A partir de ahora, la portada de la revista contendrá una fotografía asociada a la salud pública. Este año de aniversario, las fotografías tendrán un carácter histórico, con el fin de acercar al lector a diversas imágenes que muestran cómo nació en México la salud pública moderna. Dichas imágenes nos recuerdan que los enormes progresos sanitarios del país se basan en actividades pioneras, de mujeres y hombres armados con poco más que sus propias manos y su ingenio. En cuanto al contenido, queremos anunciar que en el número de mayojunio de 2004 se publicarán las nuevas Normas para la publicación de manuscritos en Salud Pública de México. Al- 
gunos cambios radican en el tratamiento que recibirán los trabajos de revisión y los ensayos, pero el más importante se centra en los aspectos éticos de los trabajos sometidos para su publicación por la revista.

La ética aplicada a las disciplinas de la salud se remonta al origen de la medicina racional, cuando surge el Juramento de Hipócrates. Todos los códigos generados a partir de ese momento coinciden en que el médico no debe hacer daño al paciente, debe intentar aliviar su sufrimiento a través de medios legítimos, y debe considerar sagrada la relación que establece con él. Aunque desde el siglo XVII el desarrollo de las ciencias de la salud implicó la participación de pacientes, sólo hasta mediados del siglo XX la ética irrumpió con fuerza en el ámbito de la investigación científica. Aunque este desarrollo fue sobre todo una respuesta a los crímenes cometidos por el ejército nazi en materia de experimentación con seres humanos, temas como el consentimiento informado han estado presentes desde la instauración de la Yellow Fever Commission en 1899. ${ }^{1}$ En 1946 nació el Código de Nuremberg sobre experimentación con seres humanos y, a partir de ese momento, surgieron los códigos de ética de las asociaciones médicas más respetadas del mundo. En 1948 la Asociación Médica Mundial formuló el Código Internacional de Etica Médica.

Con la realización del primer transplante de corazón, en 1963, numerosos interrogantes surgieron acerca de la determinación del momento de la muerte y la forma legítima para obtener el consentimiento de la donación. Más tarde, en los años sesenta, se documentó la inoculación intencional del virus de la hepatitis a niños deficientes mentales, en Willowbrook y, más tarde, se descubrió un estudio gubernamental realizado en Tuskegee, Alabama, en el que los investigadores negaron tratamiento a individuos negros afectados por sífilis, con el propósito de conocer el curso clínico de la enfermedad. La opinión pública quedó tan afectada por estos hechos que el gobierno estadounidense creó una comisión que en 1978 reformuló las reglas para realizar experimentación en seres humanos. Actual- mente, ningún país del mundo considera decente, legal o moral desarrollar investigaciones científicas que no respeten las reglas fundamentales propuestas por la bioética moderna.

Desde 1987 Salud Pública de México adoptó los criterios internacionales sobre publicación científica conocidos como Lineamientos de Vancouver. ${ }^{2,3}$ A partir de la nueva versión de nuestras normas de publicación, la mención explícita de la aprobación del proyecto de investigación por parte de un comité de ética y la obtención del consentimiento informado de los sujetos de investigación, cuando así corresponda, serán elementos indispensables para someter trabajos en la revista. Con lo anterior, Salud Pública de México se suma a las publicaciones que luchan por fortalecer una cultura del respeto de las personas mediante el uso de las normas éticas fundamentales aplicadas a la investigación.

Es justo decir que durante los 45 años de vida de Salud Pública de México han sido incontables las personas e instituciones que, de muy distintas maneras, han contribuido a su desarrollo. Queremos terminar expresando a todas ellas nuestro más amplio reconocimiento.

$$
\begin{aligned}
& \text { Carlos Oropeza* } \\
& \text { Sergio López }
\end{aligned}
$$

\section{Referencias}

1. Güereña-Burgueño F.The centennial of the Yellow Fever Commission and the use of informed consent in medical research. Salud Publica Mex 2002;44:140-144.

2. 0 ropeza-A búndez C, Atrián-Salazar ML, Fuentes-Ramírez M. N ormas para la publicación de manuscritos en Salud Pública de México. Salud Publica Mex 1997;1:75-82.

3. International Committee of Medical Journal Editors. Uniform Requirements for Manuscripts Submitted to Biomedical Journals: W riting and Editing for Biomedical Publication. Disponible en: http:// www.icmje.org/index.html\#references, consultado en abril de 2004.

\footnotetext{
* Editor Ejecutivo. Salud Pública de México.

** Editor de Sociomedicina. Salud Pública de México.
} 